\title{
Labour Market Signalling and Unemployment Duration: An Empirical Analysis Using Employer-Employee Data*
}

\author{
Anders Frederiksen, Rikke Ibsen, Michael Rosholm \\ and Niels Westergaard-Nielsen
}

Center for Corporate Performance and the Aarhus School of Business

\begin{abstract}
:
This paper tests the signalling hypothesis using detailed flow-based employer-employee data from Denmark. The primary focus is to explore how the conditions in the predisplacement firm affect the duration of unemployment. The empirical analysis is conducted within a competing risk framework, with destinations into reemployment and inactivity, which yields more plausible estimates of the signalling effect. It is established that the positive ability signal of being displaced due to a plant closure is significant but also that the signal of displacement from severe downsizing is important. Issues that have previously been ignored in the empirical analysis of the signalling hypothesis such as local labour market conditions, the sector of employment and the duration of the previous employment match are established to be important determinants for the time spent in unemployment. The heterogeneity of the signalling effect across various employee subgroups in the economy is also explored. These findings emphasize that individuals' reemployment prospects are heavily influenced by the labour market history and in particular by the conditions in the firms in which they were previously employed.
\end{abstract}

JEL classifications: J64, J65, J68

Keywords: Unemployment duration, Signalling, Plant closure

* This study is made possible by a grant from The Danish Ministry of Employment. 


\section{Introduction}

Over the past decades a vast literature of unemployment duration has emerged. Much of this literature applies search or matching models to explain transitions from unemployment and into other labour market states such as employment and inactivity. ${ }^{1}$ In general these models start when a worker is observed in unemployment and end when he leaves unemployment. The possibility that characteristics about the former employment match may influence the subsequent labour market status is in general not considered. ${ }^{2}$ This information is important for economic policy making, however, as it provides the answer to the question whether individuals displaced from severely downsizing or closing workplace require special treatment or whether the unemployment problem should be attacked more broadly.

In the seminal work by Gibbons and Katz (1991) the reason for displacement from the previous job is argued to be an important predictor for the subsequent labour market outcome of the individual due to its signalling value. The Gibbons and Katz hypothesis is based on asymmetric information arguments where the workers ability can be learned only after the employment match is formed. The firms learning process and the presence of minimum performance standards have the implication that "outside" firms infer that laid off workers will be of low ability and hence condition their hiring decision on the revealed information. Given that company closures are exogenous (not caused by the work force) no such inference can be made when displacement is caused by a workplace closure hence prospective employers can use such information as a positive signal of ability. ${ }^{3}$

Our aim in this study is to investigate whether the lay-off situation is important or not for the subsequent duration of unemployment. Specifically, we will investigate whether

\footnotetext{
${ }^{1}$ For recent surveys see Mortensen and Pissarides (1999a, 1999b).

${ }^{2}$ Heckman and Borjas (1980) and Heckman (1981) analyze the effect of lagged spells of unemployment on future unemployment and Farber (1994) peruses the dual approach and link past employment spells to the duration of current employment. These studies, however, do not explicitly integrate the characteristics of the previous employment match into the analysis.

${ }^{3}$ For an alternative discussion of the model, see Doiron (1995) or refer to the original text by Gibbons and Katz (1991).
} 
workers who lose their job as a result of workplace closures or severe downsizing have shorter periods in unemployment than others, given a comprehensive set of individualspecific explanatory variables. Furthermore, we investigate to what extent the signalling hypothesis is applicable in the economy.

The analysis is conducted using a Danish register-based employer-employee dataset that contains all displaced male workers in the Danish economy from 1994 to 2000. A preliminary analysis of these data confirms the signalling hypothesis of Gibbons and Katz (1991) in the sense that workers displaced due to workplace closures spent significant shorter time in unemployment relative to individuals displaced for other reasons. Remarkably, a deeper analysis of the data reveals that the signalling value of the lay-off condition is present in cases less extreme than workplace closures, i.e. mass lay-offs. These effects, however, are more moderate. The rationale is that the employer will always let go of the lowest ability workers first, and the larger the displaced group the noisier the ability signal becomes. This suggests that the signalling hypothesis can be applied more broadly.

A potential problem associated with measuring the signalling effect arises if the duration of unemployment for individuals who are displaced from closing workplaces is shorter because they withdraw from the labour market and not because they are reemployed. According to economic theory we will expect to see that those individuals with the lowest potential payoffs from search (lowest expected net present value of being unemployed) will be more inclined to leave the labour force. ${ }^{4}$ For this reason we hypothesize that workers who become unemployed due to workplace closures are less likely to leave the labour market than other unemployed workers, because they have unobserved abilities which increase the expected payoffs to continued search. To test this hypothesis the econometric analysis is conducted using competing risks models as in Meyer (1990) and Narendranathan and Stewart (1993).

\footnotetext{
${ }^{4}$ See for instance Frijters and van der Klaauw (2003) and Rosholm and Toomet (2005) who analyze search models with non-stationary features, thus allowing for transitions from unemployment into inactivity.
} 
An important issue for economic policy is to understand to what extent the signalling hypothesis is applicable, i.e. if it affects all employee subgroups equally. Doiron (1995) argues that the signalling effect may vary across different types of workers due to the degree of asymmetric information associated with the profession and shows that the signalling effect is absent for blue-collar workers in Canada. This result confirms a similar finding in the US provided by Gibbons and Katz (1991). In our study we cannot support this result, i.e. we find no significant variation in the signalling effect across educational groups in Denmark. Thus, according to our findings the signalling effect is an economy-wide phenomenon; at least in the Danish economy.

The duration of the previous employment spell (tenure) is an additional dimension which proves important for the individual's reemployment probability. The accumulation of specific human capital creates value in the pre-displacement match but the data shows that at the time of displacement the loss of the specific knowledge affects the reemployment prospects negatively. It is interesting to note, however, that the negative tenure effect is absent for individuals displaced from plant closures. This suggests one of two things: Either the signalling effect is sufficiently strong to make up for the negative tenure effect or individuals displaced due to plant closures are more likely to be reemployed in workplaces of similar type, i.e. reallocated within the same firm ${ }^{5}$, where the specific human capital is rewarded. ${ }^{6}$

The results have clear policy implications. Targeting employment policies at individuals displaced due to plant closures or severe downsizing is not necessarily an efficient policy as these individuals already have shorter unemployment duration. If policy interventions are deemed necessary, they should be targeted to the unemployed population in the local labour market in general.

\footnotetext{
${ }^{5}$ Frederiksen and Westergaard-Nielsen (2006) show, that $11 \%$ of all male job separations from the private sector in the Danish economy are within firm reallocations.

${ }^{6}$ Neal (1995) argues that firm-specific human capital in fact may be industry-specific human capital, which implies that the tenure effect is moderated if the individual is reemployed in the same industry.
} 
The paper is organized such that the institutional settings and the data used in the analysis are presented in the next section. In section 3 the empirical model is outlined. The results are discussed in section 4. In section 5 economic policy issues are addressed. Finally, section 6 summarizes and concludes.

\section{Institutional settings and preliminary examination of the data}

\subsection{Institutional settings}

The Danish labour market is characterized by a high degree of unionization and instant access to unemployment benefits when a worker is laid off. For workers who have paid unemployment insurance for at least one year and worked at least 52 weeks in the three years prior to losing their jobs, the unemployment insurance (UI) benefit is $90 \%$ of the monthly salary up to a maximum of $€ 1770$ per month (1999-level). This implies that low-wage workers receive UI benefits very close to their former salary, while high-wage workers face a large cut in income when they lose their jobs. UI benefits are paid for up to four years after which an individual is eligible for social security benefits. Workers who are not insured may receive social security benefits from the first day of unemployment, conditional on actively searching for employment. ${ }^{7}$

One reason for the high degree of unionization is that unions and unemployment insurance funds are linked together, so when a worker joins one he more or less automatically joins the other as well. Another reason is that union membership is an insurance against 'unfair' lay-offs, since the union will assist the laid-off worker in complaining and ultimately going to court.

The easy access to UI benefits makes it almost costless for employers to lay off workers when business is slow, since the cost is on the public sector through unemployment insurance benefits (which is heavily subsidized by the state) or social security benefits. The employer only pays for the worker's first two days of unemployment.

\footnotetext{
${ }^{7}$ Social security benefit is unlike UI means tested and in principle paid according to need.
} 
The private sector in Denmark does not have seniority rules, so the laid-off worker is not automatically the last hired person. This means that it is reasonable to assume that the laid-off worker from a workplace is the least productive, unless the workplace is closing.

The advance notice rules for lay-offs differ for salaried workers (white collar workers) and workers paid by the hour (blue collar workers). Salaried workers are protected by law to have minimum 2 weeks' notice the first 6 months of employment with the same employer and minimum 6 months after 9 years of employment. This law applies to all salaried employees working more than 8 hours a week on average. For blue collar (hourly paid) workers no advance notice law applies, but in some labour contracts advance notice rules are agreed upon locally between the employer and the employees. These are in all cases much lower than for salaried employees. Only in the case of mass lay-offs there are advance notice rules for blue collar workers.

\subsection{Data}

Center for Corporate Performance (CCP) has constructed a register-based employeremployee dataset referred to as the 'event history data set', which contains weekly information about the occupational state of all persons aged 16-75 during the period 1986-1999. The event history data set is a flow data set in the sense that all transitions between the three states employment, unemployment and inactivity are recorded. In addition, the data set contains a rich set of individual characteristics and extensive information about the previous employer for all workers. Important to note is the high frequency of the data which makes it possible to obtain the actual number of transitions that occur - not only from year to year - but also all transitions in between.

\subsection{Sample selection and data description}

From this data set we extract all unemployment spells beginning in the period 1994-1999, because the quality of the information on unemployment is much better during this period than in the period 1986-1993. Only individuals whose previous employment was in a private workplace with 20 employees or more are selected. Persons becoming 
unemployed from a job in the public sector or smaller firms are thus eliminated from the data set, as are labour market entrants and re-entrants.

Unemployment spells come to a stop if the person leaves the labour force or finds a new job. If the unemployment spell continues until the sample observation period ends, the observation is right-censored.

The workplace that displaces the worker is either closing, upsizing, downsizing or unchanged in terms of employment. Displaced workers from workplaces that are part of a merge or spin-off will not be part of the data set, since the signals from these workplace changes are likely to differ from the changes in workplaces that have not changed structure. This restriction on the data set removes $17 \%$ of the unemployment spells.

The data set is constructed to analyze workplaces rather than firms. Since we will be looking at the importance of the local labour market, an analysis at the firm level will be too crude. Firms will often be located in more than one area, while a workplace by definition is situated at one location. Hence, the information on the previous employer refers to the workplace rather than the firm.

Persons being under the age of 18 at the beginning of the unemployment spell and more than 59 years at the end of the unemployment spell are also removed from the data set. The reason is to eliminate any effects from early retirement. The last restriction is that temporarily unemployed persons, defined as unemployed individuals that return to their former employer, are not included either.

The data set used in the analyses below contains 128,241 male workers who have a total of 157,038 unemployment spells, see Table 1 . Out of these, less than $5 \%$ were rightcensored. $81 \%$ of the uncensored spells ended in a transition back into employment, while $19 \%$ ended in a transition into inactivity. Average unemployment duration is slightly above 28 weeks, which is quite long, but this is a result of removing temporary lay-offs, which are typically very short (nearly $90 \%$ of these are shorter than 5 weeks). 
Averages of explanatory variables used in the analysis are shown in Table 1 . These are defined and described in more detail in Table A1 in the Appendix. The explanatory variables are recorded at the beginning of each unemployment spell, i.e. at the time a person loses his job. Since we are not exploiting the information on repeated spells for each person, the spells are perceived as single spells even though they might happen to the same person. Therefore the descriptive statistics describe the explanatory variables with the unemployment spell as the unit of analysis.

The duration of the employment spell prior to the unemployment spells is on average 77 weeks or 1.48 years, which is rather short compared to total working experience, which is more than 10 years on average. This highlights the fact that worker turnover is very high on the Danish labour market, a fact that was documented by Frederiksen and Westergaard-Nielsen (2006).

The largest age group of displaced workers is $20-29$ years old; they account for $40 \%$ of the unemployment spells, while workers 30-39 years of age account for $25 \%$. More than half of the displaced workers have 10-12 years of education, while $40 \%$ have no further education exceeding basic education.

Turning to unemployment insurance fund membership, manufacturing is by far the largest with 37\%, metal and construction each account for $11 \%$ and workers who are not insured have $17 \%$ of the unemployment spells. It is important to bear in mind that we did not include temporary lay-offs in the duration data set. 
Table 1. Descriptive statistics for spells.

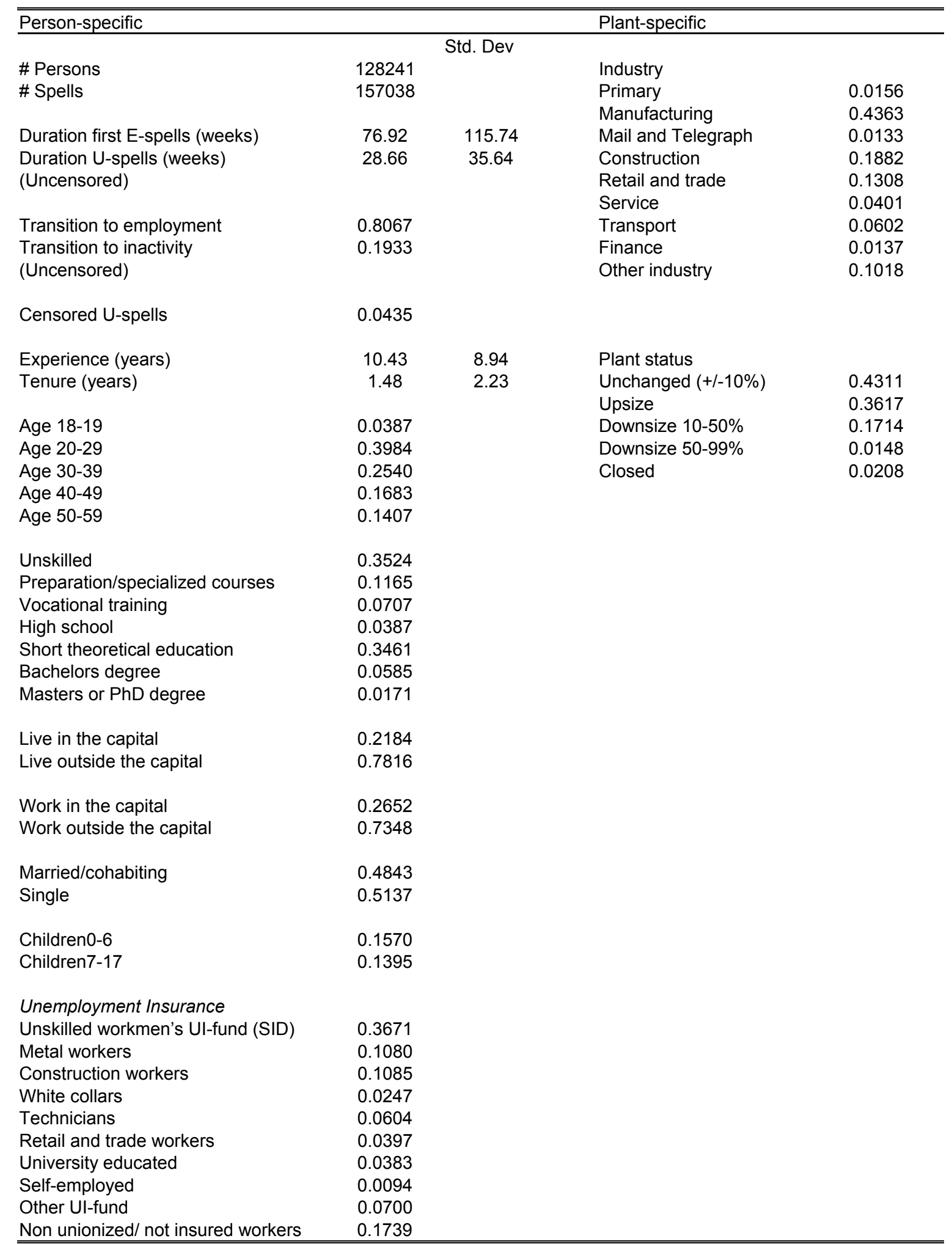

Note: The table is in 2 parts; the first column contains person-specific variables and the second column contains workplace-specific variables. 
Turning to workplace-specific descriptive statistics, the workplace status is dominated by workplaces with unchanged size and workplaces that are upsizing, while workplaces downsizing (10-50\%) and severely downsizing (50-99\%) together only amount to half the fraction of upsizing workplaces. Only $2 \%$ of the displaced workers are laid off from a closing workplace. Manufacturing, construction and trade are the industries that have the largest fractions of lay-offs.

\subsection{Empirical hazard models}

The aim of this paper is to examine if there is a signalling effect from lay-offs due to workplace status. As a preliminary step we look at the non-parametric empirical hazard rates out of unemployment divided into lay-offs from closed workplaces and workplaces where the size is 'unchanged' (that is, the change is less than 10\%).

Figure 1 shows the Kaplan-Meier estimates of the empirical hazard rates out of unemployment into employment for workers laid off from 'unchanged' workplaces and from workplaces that have closed down entirely. This hazard rate is clearly larger for workers laid off from a closing workplace than an unchanged workplace during the first 30 weeks of an unemployment spell. After the first 30 weeks the difference disappears, but there are also fewer observations at this point and the standard deviations are high.

Figure 2 shows the empirical hazard from unemployment and out of the labour force. ${ }^{8}$ The difference in the hazard rates between workers from closed and unchanged firms is less pronounced for this transition, but workers laid off from closing workplaces appear to be less inclined to leave the labour force than workers leaving an unchanged workplace for the whole period.

These results thus appear to be in accordance with our a priori expectations, but formal tests of significant differences are deferred to the next section, where we correct for

\footnotetext{
${ }^{8}$ Notice that these hazard rates are much smaller than those in Figure 1.
} 
differences in observed characteristics of the workers, that is, we estimate parametric duration models. These are described in the next section.

Figure 1. Empirical hazard for transitions from unemployment into employment for workers coming from closed and continuing workplaces (unchanged).

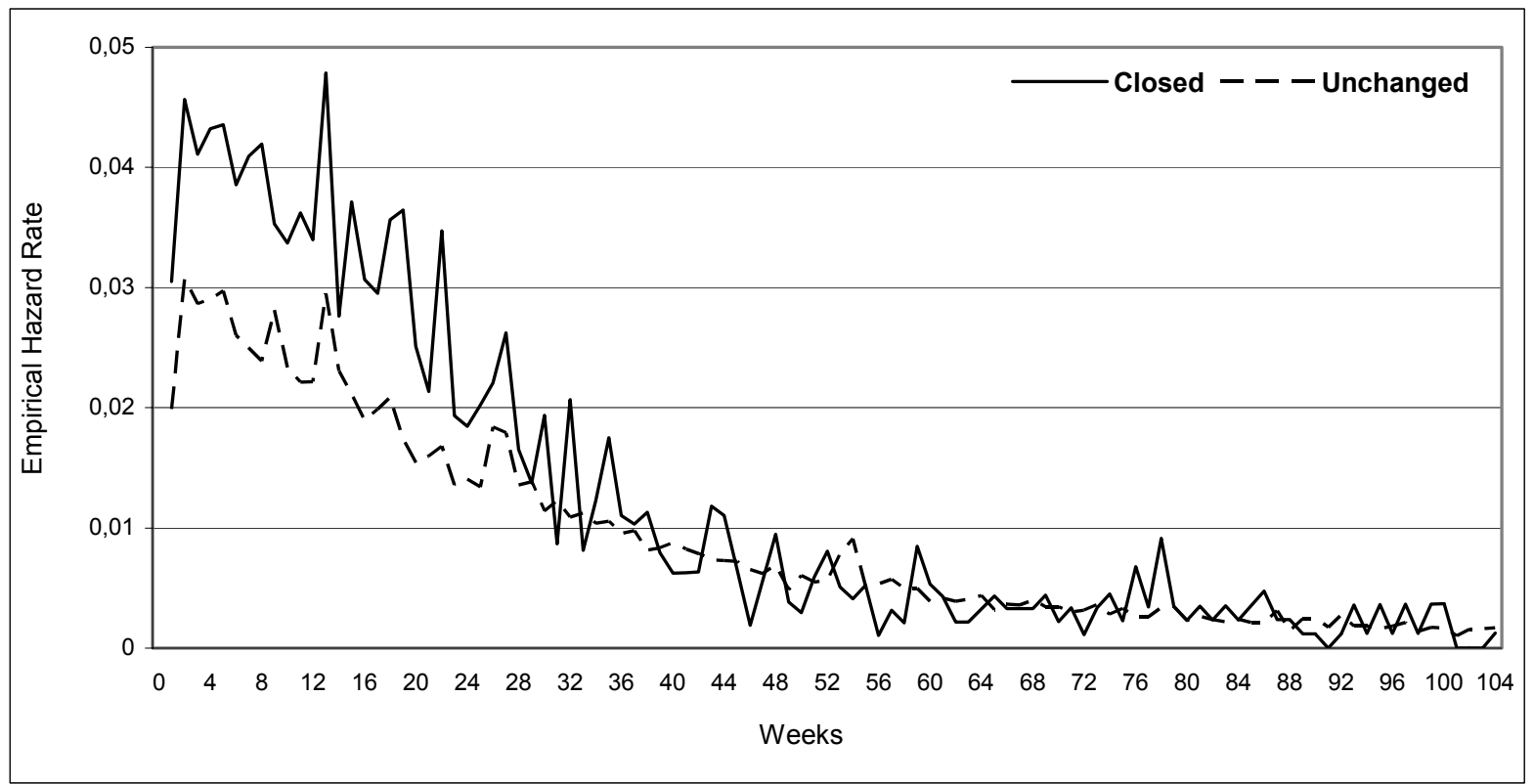

Figure 2. Empirical hazard for transitions from unemployment into inactivity.

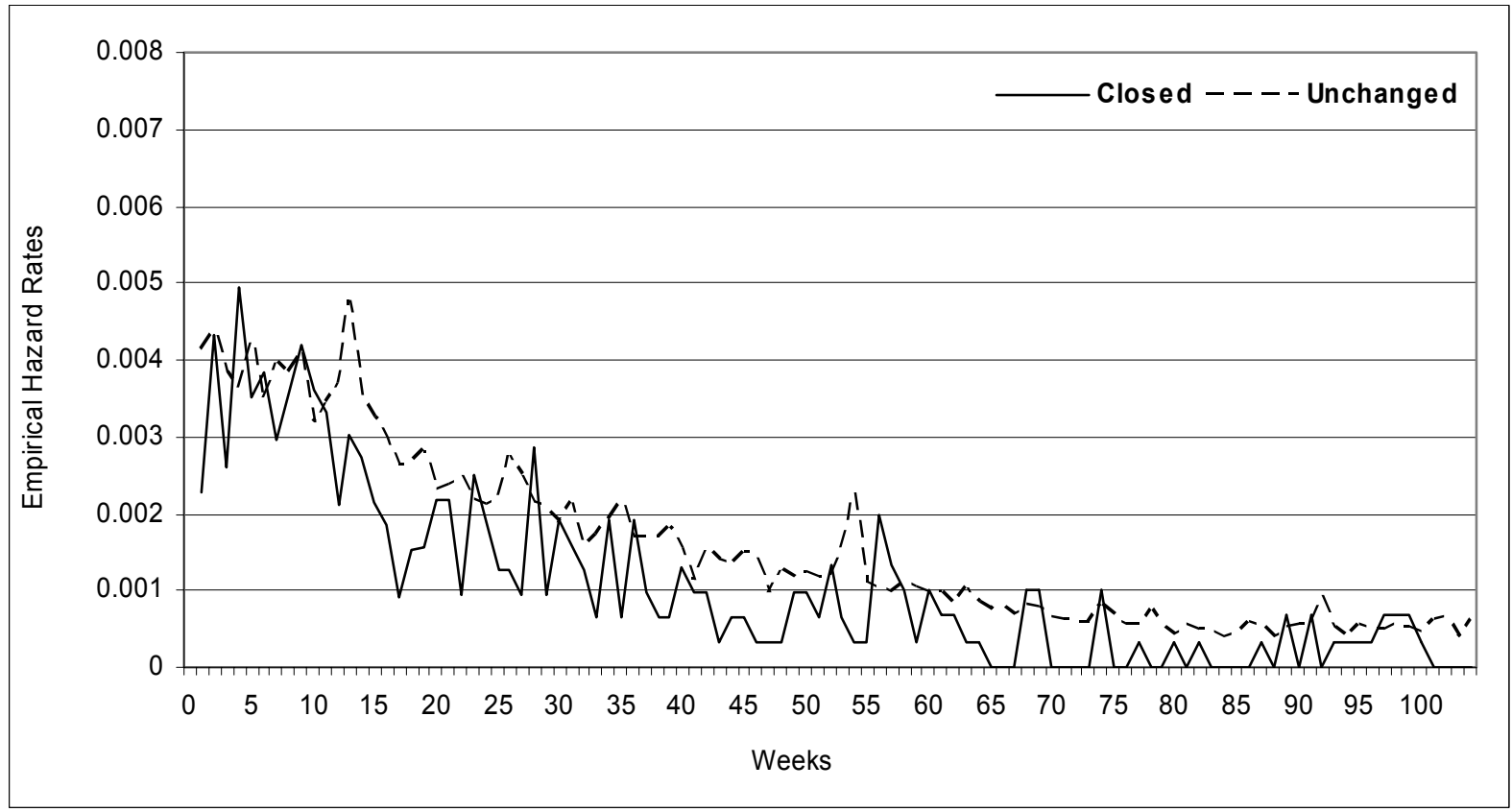




\section{The econometric model}

This section describes the econometric model used to investigate how the closure variables, which are interpreted as ability signals, affect individual transitions out of unemployment. We are interested in modelling the transition out of unemployment and into either employment or inactivity. Therefore, we will employ a competing risks duration model.

Let the continuous random variable $T, T \in(0, \infty)$, denote unemployment duration. The hazard rate, which denotes the rate at which an individual with observed characteristics $x$ leaves unemployment just after time $t$ given that the individual is still unemployed at time $t$, is then given by

$$
h(t \mid x)=\lim _{d t \rightarrow 0} \frac{P(t<T \leq t+d t \mid T>t)}{d t}
$$

In a competing risks model, this hazard rate is the sum of two destination-specific hazard rates, one for entering each of the two states employment (E) and inactivity $(\mathrm{N})$. The destination-specific hazard functions are specified as proportional hazards, that is, the destination-specific hazard rate is the product of the baseline hazard, which captures the time dependence of the destination-specific hazard rate, and a function of observed characteristics

$$
h_{i}(t \mid x)=\lambda_{i}(t) \cdot \exp \left(x \beta_{i}\right), \quad i=E, N .
$$

Let $d_{E}=\mathrm{I}_{\{i=E\}}, d_{N}=\mathrm{I}_{\{i=N\}}$ denote two destination state indicators for the events in the brackets. We assume that the baseline hazard rates are piecewise constant, that is,

$$
\lambda_{i}(t)=\exp \left(\alpha_{i, k(t)}\right), \quad i=E, N
$$


where $k(t)$ is a function which maps a duration $t$ into an interval in the baseline function. $K$ is the number of intervals for the baseline hazard. Notice that the baseline hazard can be made arbitrarily flexible by increasing the number of intervals. The contribution to the likelihood function by a single unemployment spell can now be written as

$$
L(\theta)=\left[h_{E}(t \mid x)\right]^{d_{E}} \cdot\left[h_{N}(t \mid x)\right]^{d_{N}} \cdot S(t \mid x),
$$

where $\theta$ denotes the entire parameter vector to be estimated, and

$$
S(t \mid x)=\int_{0}^{t}\left(h_{E}(s \mid x)+h_{N}(s \mid x)\right) d s
$$

is the survivor function, i.e. the probability of remaining unemployed after $t$ weeks. To obtain the point estimates we apply maximum likelihood estimation on the product of likelihood contributions from all unemployment spells.

Note, that according to the signalling hypothesis information about the reason for job displacement is a signal about the unobserved characteristics of the individual worker. Hence, any attempt to correct statistically for unobserved heterogeneity in this study would correspond to throwing out the baby with the bathwater.

\section{Empirical results}

In this section the signalling hypothesis is studied. First, we present the basic model, in terms of the covariates included, that will be used throughout the investigation. Second, the signals are introduced into the analysis and their ability to predict the labour market outcome of the displaced workers is addressed. Finally, several extensions are made in order to assess to what extent the signalling hypothesis is applicable in the economy. 


\subsection{The basic model}

The estimated baseline hazard rates are shown in Figure 3. They reveal that while the likelihood of returning to work is declining over time, the likelihood of leaving the workforce increases.

Figure 3. Estimated baseline hazard rates normalized to 1 in period one.

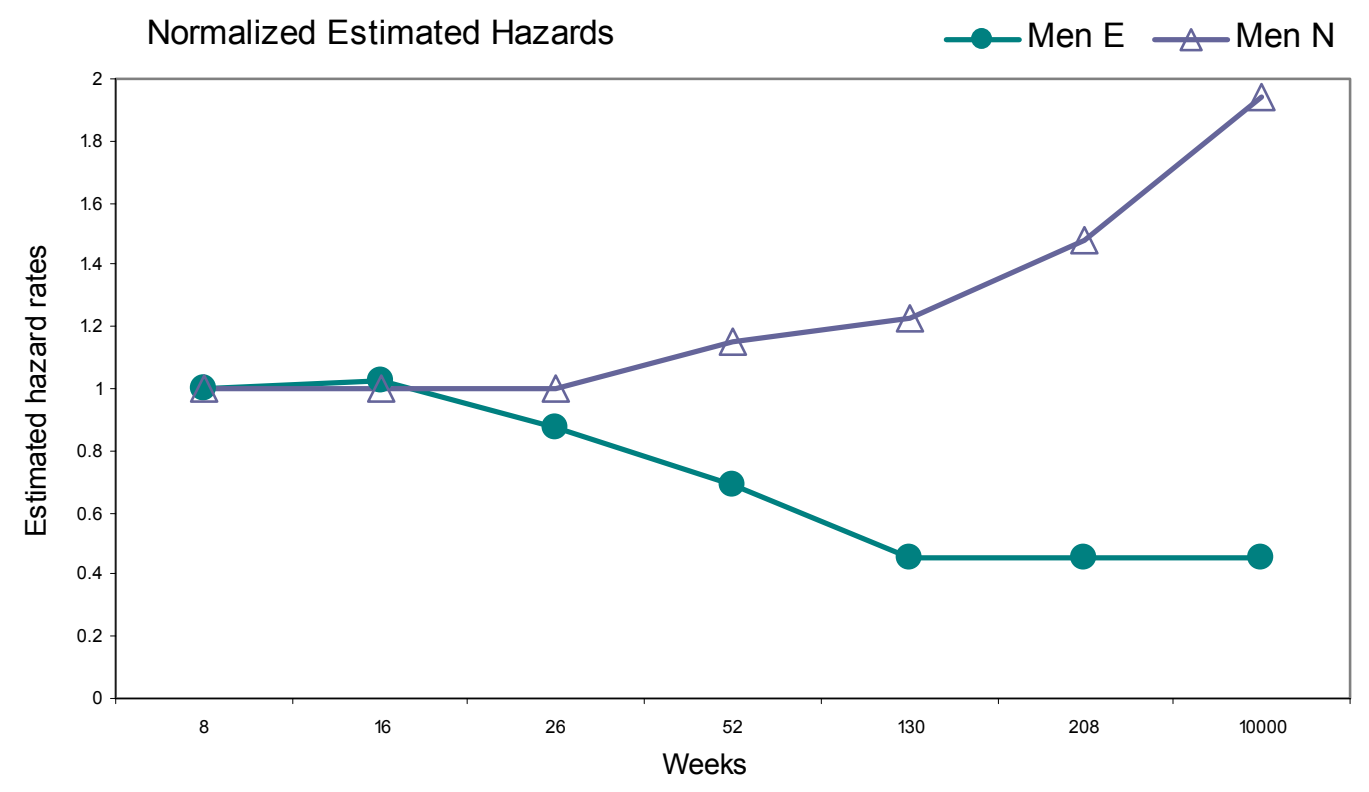

The effect of the covariates in the basic model is presented in Table 2 . The effect of the previous employment match on the duration of unemployment is measured by functions of the time spent with the former employer (tenure). There is clearly a negative effect on the reemployment probability from tenure. Note that the tenure effect is conditional on work experience (which includes tenure in the previous firm) so the interpretation is that individuals with high tenure have lower transition rates from unemployment to employment than a worker with similar levels of work experience, but with shorter tenure in the last job. This effect is most likely to arise because of investments in specific human capital. ${ }^{9}$ The reason is that high-tenured individuals have relatively higher levels of

\footnotetext{
${ }^{9}$ An alternative argument is that tenure is a signalling device. For instance, long tenure implies that the employee has survived in the firm (avoided being fired) for a relatively long period. This could in principle be interpreted as a positive signal. However, even though the firm can improve the quality of the workforce through lay-offs, it does not imply positive selection on tenure. The reason is that firms over time may lose high-quality workers in competition with other firms which naturally reduces average employee quality.
} 
specific human capital and thus relatively higher wages. If the higher wages affect the individuals' search behaviour through higher reservation wages, then longer unemployment spells are expected. The negative effect of the duration of the employment spell is somewhat moderated by the positive influence of work experience. The presence of these effects emphasize that information about the employees work history is important in predicting the individual's reemployment prospects.

Another aspect of the worker's previous employment history is information about the industry in which he has been working. In the model this is captured by eight industry dummies. Workers in the construction industry clearly have the highest likelihood of returning to work relative to all other groups. This is naturally reflecting the nature of the work in the industry, where it is common to change employers due to the large variations in labour demand. This result would have been even stronger if temporary employees were included in the analysis. In the largest industry (manufacturing), which accounts for $44 \%$ of the sample, it is relatively difficult to find a new job once unemployed. These difficulties are only exceeded in the financial sector.

In the analysis conducted by Gibbons and Katz (1991) local labour market conditions were ignored. They pointed out, however, that this potentially would lead to bias in the signalling effect since it is easier for the labour market to absorb a single individual as opposed to all the individuals simultaneously leaving a closing workplace. For this reason we include the unemployment rate in the local labour market (municipality) in the model and find a strong negative effect from high unemployment on the reemployment probability. Following this line of thought we further add information about the local labour market by including a dummy for living in the Metropolitan area (in and around Copenhagen) and a dummy for having worked in the Metropolitan area in the previous job. Both of these have a positive effect on reemployment reflecting that it is easier to find job in a large labour market.

This means that tenure has an ambiguous effect on employee quality and depends crucially on the sorting and selection taking place in the individual firm. This discussion comes close to the arguments used in Frederiksen and Takáts (2005) who analyze within organizational rank employee selection. They show that the firm's selection scheme on tenure can be either positive or negative depending on the policies used for employee sorting. 
The results discussed above are conditional on holding a large set of demographic and educational variables fixed. In particular, middle-aged workers (30 to 50 years of age) are less likely to return to employment than younger workers and more likely than senior workers. Thus, the younger the workers are, the faster they return to job. Also, family related variables such as children and marriage have that effect. Finally, education significantly improves the likelihood of being reemployed.

The transition from unemployment and into inactivity is another aspect that influences the duration of unemployment. In general, many of the variables discussed above have significant effects on the transition rate into inactivity. Important to note, however, is that the effects of the covariates on the probability of a transition out of the labour market are of different magnitude and often of opposite sign when compared to the effects they have on transitions back into employment. Hence, the distinction between exit states is highly relevant.

A highly intuitive result is that more senior individuals tend to withdraw from the labour market. In Frederiksen and Westergaard-Nielsen (2006) where the transitions out of jobs were modelled, remarkably few workers were found to leave employment for retirement. The results in Table 2 indicate that unemployment is the channel which is being used to move from employment and into retirement.

According to theory it is expected that the better reemployment prospects in a tight labour market will increase the value of continued job search relative to the state of inactivity making workers less likely to leave the labour force in economic peaks. For this reason it is somewhat surprising that a higher local unemployment rate plays no role for the decision to leave the labour force. One interpretation could be that other and more diffuse reasons are more important when making this decision; in particular when the decision is heavily influenced by the UI system. 
Table 2. Competing risk hazard model with destinations into employment and inactivity.

\begin{tabular}{|c|c|c|}
\hline & & \\
\hline & Employment & Inactivity \\
\hline Age less than 30 years & $0.411(0.008)$ & $0.033(0.018)$ \\
\hline Age above 50 years & $\mathbf{- 0 . 4 9 2}(0.012)$ & $\mathbf{0 . 2 8 4}(0.023)$ \\
\hline Married/cohabiting & $\mathbf{0 . 1 3 2}(0.008)$ & $-\mathbf{0 . 0 3 1}(0.016)$ \\
\hline Children under 7 years & $-0.005(0.009)$ & $-\mathbf{0 . 0 7 3}(0.022)$ \\
\hline Children 7 to 17 years & $\mathbf{0 . 0 8 0}(0.010)$ & $-\mathbf{0 . 0 9 2}(0.022)$ \\
\hline Unskilled & - & - \\
\hline Preparation/specialized courses & $\mathbf{0 . 1 3 1}(0.010)$ & $0.016(0.020)$ \\
\hline Vocational training & $0.114(0.018)$ & $-0.008(0.042)$ \\
\hline High school & $\mathbf{0 . 1 5 7}(0.017)$ & $\mathbf{0 . 3 7 7}(0.029)$ \\
\hline Short theoretical education & $0.213(0.008)$ & $0.030(0.016)$ \\
\hline Bachelors degree & $\mathbf{0 . 2 6 7}(0.016)$ & $\mathbf{0 . 1 2 5}(0.033)$ \\
\hline Masters or $\mathrm{PhD}$ degree & $\mathbf{0 . 2 3 8}(0.029)$ & $\mathbf{0 . 1 3 9}(0.057)$ \\
\hline Live in Capital & $\mathbf{0 . 0 4 1}(0.010)$ & $0.025(0.021)$ \\
\hline Worked in Capital & $\mathbf{0 . 0 9 0}(0.010)$ & $\mathbf{0 . 0 8 3}(0.020)$ \\
\hline Local unemployment rate & $\mathbf{- 0 . 3 4 0}(0.012)$ & $-0.008(0.026)$ \\
\hline Tenure 1 to 2 years & $\mathbf{- 0 . 1 7 0}(0.009)$ & $\mathbf{- 0 . 0 5 4}(0.018)$ \\
\hline Tenure 2 to 5 years & $\mathbf{- 0 . 2 3 5}(0.009)$ & $-\mathbf{0 . 1 0 5}(0.019)$ \\
\hline Tenure 5 to 10 years & $\mathbf{- 0 . 4 9 0}(0.015)$ & $0.005(0.026)$ \\
\hline Tenure above 10 years & $\mathbf{- 0 . 5 0 6}(0.033)$ & $-0.028(0.051)$ \\
\hline Experience 1 to 2 years & $\mathbf{0 . 0 3 8}(0.016)$ & $-\mathbf{0 . 0 6 5}(0.026)$ \\
\hline Experience 3 to 5 years & $\mathbf{0 . 1 4 2}(0.014)$ & $-\mathbf{0 . 1 4 4}(0.023)$ \\
\hline Experience 6 to 10 years & $0.245(0.014)$ & $-\mathbf{0 . 2 8 7}(0.025)$ \\
\hline Experience 11 to 20 years & $0.375(0.015)$ & $-\mathbf{0 . 3 6 1}(0.028)$ \\
\hline Experience above 20 years & $\mathbf{0 . 3 2 2}(0.017)$ & $-\mathbf{0 . 3 9 6}(0.032)$ \\
\hline Manufacturing sector & - & - \\
\hline Primary sector & $0.149(0.025)$ & $0.008(0.048)$ \\
\hline Mail and telegraph sector & $0.009(0.030)$ & $0.086(0.048)$ \\
\hline Construction sector & $0.418(0.008)$ & $\mathbf{- 0 . 1 6 1}(0.021)$ \\
\hline Retail and trade sectors & $0.113(0.010)$ & $\mathbf{- 0 . 0 8 9}(0.020)$ \\
\hline Service sector & $0.220(0.017)$ & $-\mathbf{0 . 1 2 6}(0.033)$ \\
\hline Transportation sector & $\mathbf{0 . 1 6 3}(0.014)$ & $-0.009(0.027)$ \\
\hline Finance sector & $\mathbf{- 0 . 1 1 2}(0.029)$ & $0.015(0.049)$ \\
\hline Other sector & $\mathbf{0 . 1 1 3}(0.012)$ & $-0.010(0.022)$ \\
\hline Unskilled workmen's UI-fund (SID) & - & - \\
\hline Non unionized/ not insured workers & $-\mathbf{0 . 0 8 2}(0.010)$ & $\mathbf{0 . 3 2 6}(0.019)$ \\
\hline Construction workers & $\mathbf{0 . 2 5 6}(0.010)$ & $\mathbf{0 . 1 0 5}(0.027)$ \\
\hline Metal workers & $\mathbf{0 . 0 9 3}(0.011)$ & $\mathbf{0 . 0 9 6}(0.024)$ \\
\hline Technicians & $-\mathbf{0 . 2 1 0}(0.015)$ & $-\mathbf{0 . 1 1 6}(0.029)$ \\
\hline Retail and trade workers & $\mathbf{- 0 . 1 8 4}(0.017)$ & $-\mathbf{0 . 0 7 1}(0.034)$ \\
\hline White collars & $\mathbf{- 0 . 0 7 9}(0.021)$ & $-\mathbf{0 . 2 3 5}(0.046)$ \\
\hline University educated & $\mathbf{- 0 . 0 7 1}(0.022)$ & $-\mathbf{0 . 1 6 6}(0.045)$ \\
\hline Self-employed & $\mathbf{- 0 . 4 8 9}(0.031)$ & $-1.199(0.079)$ \\
\hline Other UI-fund & $\mathbf{- 0 . 1 0 3}(0.013)$ & $-0.016(0.026)$ \\
\hline Log likelihood & & \\
\hline \# observations & & \\
\hline
\end{tabular}

Note: Standard errors are in parentheses. Coefficients written in bold are statistically significant at the 5\% level. 
Unemployment insurance fund membership captures in part the impact of economic incentives and in part differences across skill-groups and industry, since UI funds are organized around skill levels and industry. These coefficients are not given a causal interpretation in this context hence we will not discuss them further.

\subsection{The signalling hypothesis}

In the discussion of the basic model (model (1), Table 2), information about the previous employment match, such as industry and tenure, is used to explain the duration of unemployment. In Table 3 this analysis is extended by introducing signals indicating the reason for displacement as suggested by the signalling hypothesis. Models (2) and (3) in Table 3 use the same set of explanatory variables as the one included in model (1). The detailed results are not shown due to space concerns but the point estimates are highly robust to the inclusion of the signals. ${ }^{10}$

In model (2) a dummy indicating that the individual is displaced from a closing firm is added to the model. As predicted by the signalling hypothesis, employees displaced due to a workplace closure have a significantly higher probability of getting a new job. The dual prediction is that this group of individuals also has a lower probability of leaving the labour force. This effect, while present, is not statistically significant in this first specification of the model.

The signal used in model (2) is that the worker is coming from a workplace closure and the effect of this signal is compared to a reference group of individuals who are displaced for any other reason. It is likely, however, that the signals carried by the individuals in the reference group may be heterogeneous. An obvious example is that when the firm dismisses the individual with the lowest ability first, individuals displaced from mass layoffs (close to 100\%) will carry signals almost similar to individuals displaced from workplace closures. The quality of the signal will then be determined by the seriousness of the downsizing. The empirical results presented in model (3) support this hypothesis by the indication of a clear decline in the signalling value as the downsizing of the firm

\footnotetext{
${ }^{10}$ Results are available from the authors on request.
} 
moves from complete closure to individual lay-offs. The signal arising from leaving an expanding firm seems to have only little importance for the probability of being reemployed.

Table 3. Competing hazard models with signals. Standard errors in parentheses.

\begin{tabular}{|c|c|c|c|c|}
\hline & \multicolumn{2}{|c|}{ Model (2) } & \multicolumn{2}{|c|}{ Model (3) } \\
\hline & Employment & Inactivity & Employment & Inactivity \\
\hline Closure & $\begin{array}{c}\mathbf{0 . 2 2 3} \\
(0.019)\end{array}$ & $\begin{array}{l}-0.080 \\
(0.050)\end{array}$ & $\begin{array}{c}\mathbf{0 . 2 3 7} \\
(0.019)\end{array}$ & $\begin{array}{c}\mathbf{- 0 . 1 0 4} \\
(0.051)\end{array}$ \\
\hline Downsize 50 to $99 \%$ & - & - & $\begin{array}{c}\mathbf{0 . 1 1 3} \\
(0.025)\end{array}$ & $\begin{array}{l}-0.062 \\
(0.052)\end{array}$ \\
\hline Downsize 10 to $50 \%$ & - & - & $\begin{array}{c}\mathbf{0 . 0 2 8} \\
(0.009)\end{array}$ & $\begin{array}{l}-\mathbf{- 0 . 0 5 4} \\
(0.018)\end{array}$ \\
\hline Expanding firm & - & - & $\begin{array}{c}\mathbf{0 . 0 1 8} \\
(0.007)\end{array}$ & $\begin{array}{l}-\mathbf{- 0 . 0 6 7} \\
(0.014)\end{array}$ \\
\hline $\begin{array}{l}\text { No change in employment } \\
(+/-10 \%)\end{array}$ & - & - & - & - \\
\hline $\begin{array}{l}\text { Log likelihood } \\
\text { \# observations }\end{array}$ & \multicolumn{2}{|c|}{$-667,925$} & \multicolumn{2}{|c|}{$-667,905$} \\
\hline
\end{tabular}

Note: The control variables in models (2) and (3) are similar to model (1) which is presented in Table 2. Their effects on the transitions out of unemployment have not been altered by the introduction of the additional signalling variables. The reference category for the closure variable in model (2) is everybody displaced for other reasons than a workplace closure. In model (3) the reference is those individuals displaced from workplaces with "no change in employment". Coefficients written in bold are statistically significant at the $5 \%$ level.

The decomposition of the reference group is also important for the influence on the transitions out of unemployment and into inactivity. As predicted by theory the closure signal now becomes significantly negative indicating that individuals displaced from workplace closures have unobserved abilities that increase the expected payoffs to continue searching for a new job. In general, the unemployed worker who can send a signal that is different from leaving a workplace with stable employment has a lower likelihood of moving out of the labour force. However, these effects are smaller in magnitude than the impacts on the hazard rate into employment, and fewer of the effects are statistically significant.

The signalling effects are sizeable and hence economically important. An individual who is displaced from a closing firm has a transition rate into employment that is $27 \%$ larger 
$(\exp [0.237]=1.27)$ than that of a worker who is displaced for reasons other than downsizing. Similarly, he has a risk of leaving the labour force which is $10 \%$ smaller than that of an ordinarily laid-off worker.

\subsection{Heterogeneity in the signalling effect}

The signalling effects for the individuals displaced from closing and downsizing plants estimated in the above regressions reflect the average effect for all the employees in the sample. It is likely, however, that these effects are heterogeneous across individual subgroups as the level of asymmetric information may vary across industries and across skill groups, see Gibbons and Katz (1991) and Doiron (1995).

The first question to be addressed is whether the signalling effect is heterogeneous across individuals with different levels of education. This is the case if the information a potential employer can infer from a lay-off varies across skill groups. For instance, if some professions (low-skilled or high-skilled professions) are subject to last-in-first-out rules or other non-competitive rules that create uncertainty about the quality of the employees who are fired, then the signalling value will be heterogeneous across subgroups.

Our estimation strategy for detecting signal heterogeneity (interaction effects) is to estimate a model with interaction between the three signalling variables of closure and downsizing on one side and education, tenure and industry on the other side. We would then sequentially test the model down by applying likelihood ratio tests to those sets of interactions which appeared to have the lowest t-statistics. As a result, all interactions between signals and education disappeared, as there was not a single coefficient which was statistically significant. This implies that the signalling effect (due to the level effect) is significant and constant across educational groups. This observation contradicts the findings in Gibbons and Katz (1991) and Doiron (1995) who find that the signalling effect is absent for blue-collar workers. 
Table 4 presents the results for those sets of interactions between industry and tenure on the one side and signals on the other, which we could not remove based on LR tests. Here we present only interactions for the hazard rate into employment, as there were few significant interaction effects in the hazard rate into inactivity. The general picture which emerges with respect to tenure is that the overall negative effects of tenure (conditional on work experience) are modified by the cause of displacement. Namely, the signalling effect increases strongly with tenure, especially for the strongest of the signals (closure). This suggests that under some circumstances, high tenure sends a strong signal, but if a high tenure individual is laid off 'on his own', then it sends a signal that he was fired in spite of having high tenure, which may be a signal of low ability. For closure- and downsizing-related lay-offs, however, having some tenure sends a better signal than not having tenure. It could also be that they tend to get a job, where they are able to use their specialized human capital. For instance, Frederiksen and Westergaard-Nielsen (2006) show that $11 \%$ of the male individuals leaving a closing workplace are reemployed in a different workplace within the same firm in the following year. Hence, it is a possibility that some employees are transferred to another workplace in the same firm where they can re-use their firm-specific capital. Another explanation is that they may find a new job in the same industry and thus are able to use their industry-specific capital, which is positively related to firm-specific tenure. See Neal (1995) for a related discussion.

With respect to interactions between industry and signal, it appears that the signalling effect is only generally present in manufacturing (the reference category); i.e. both the closure and downsizing effects are significant. In most other industries the downsizing signalling effect is only present for high-tenured individuals. These results may partly be due to small signal-industry cell sizes.

The above discussion underlines the importance of the signalling hypothesis and points at the relevance of including information about the previous employment match such as sector, tenure and the condition leading to unemployment when assessing the displaced worker's reemployment prospects. In the next section we will discuss how these observations should affect economic polity. 
Table 4. Interactions effects between the signals and industry and tenure, respectively.

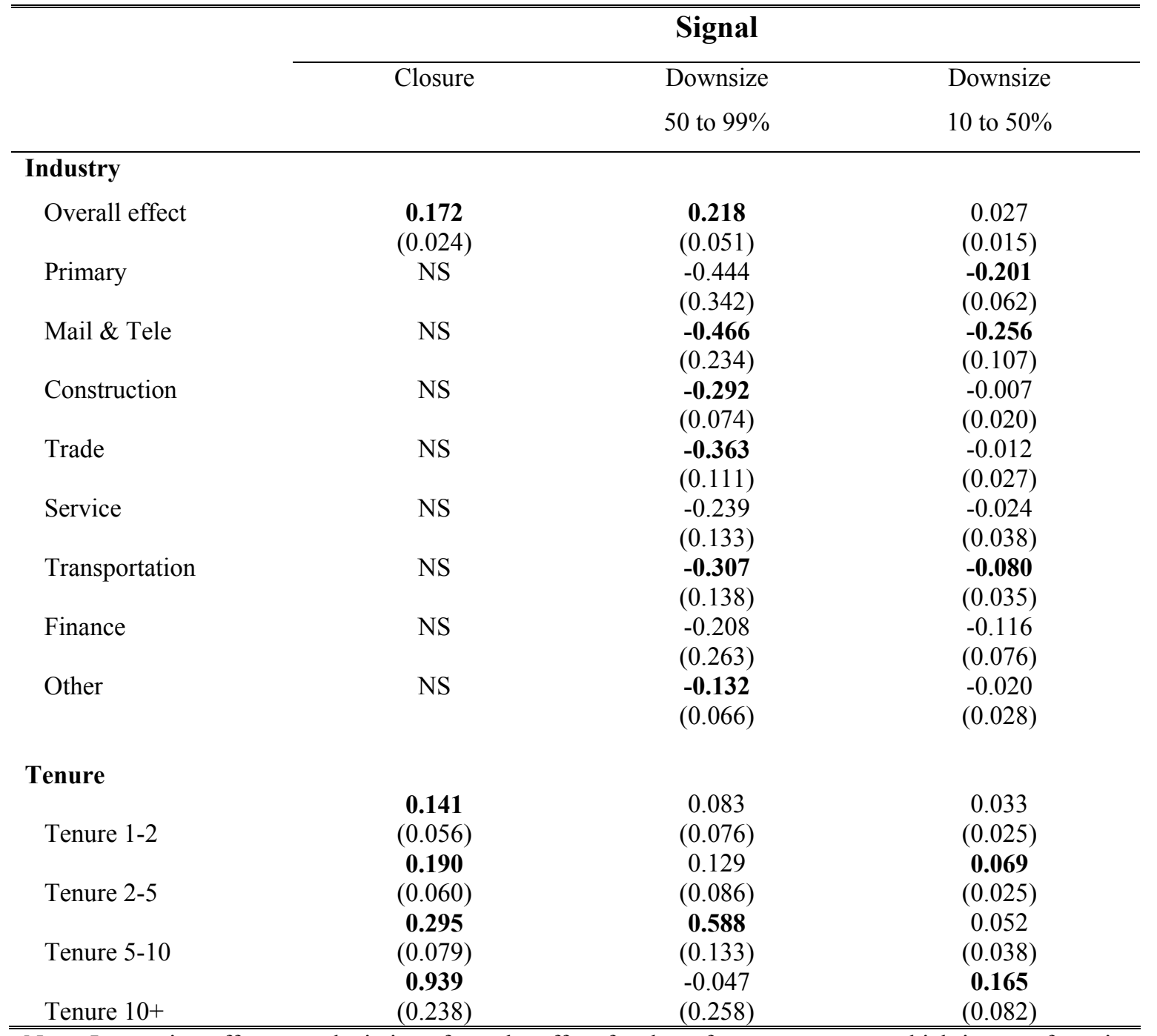

Note: Interaction effects are deviations from the effect for the reference category, which is manufacturing industry and tenure 0 to 1 year. NS means 'not significant' based on joint likelihood ratio test. The results in the first column show the interaction effects between closure and industry and tenure, respectively. The last two columns show interactions between the downsizing signals and tenure and industry.

\section{Economic policy issues}

There are two important things to keep in mind when discussing policy-related issues. First, the hazard rate into employment decreases with the local unemployment rate, hence, workplace closures and mass lay-offs which have a non-negligible impact on the local unemployment rate warrant a consideration of whether policy intervention is relevant. If it is, the results clearly suggest that policies should not be aimed at those workers who are the direct 'victims' of mass lay-offs, since they have better than average 
job prospects in the local labour market. Rather, the policy should be directed at unemployed workers in the local labour market in general, or perhaps even targeted at those workers whose skills are least in demand. Second, the target groups of a policy intervention naturally depend on the objective of the policy; egalitarianism or efficiency. An egalitarian policy would suggest aiming policies at those with the worst job prospects as suggested above, while an efficient policy would be aimed at those whose job prospects would improve the most as a result of the policy intervention - those with the largest treatment effect.

\section{Conclusion}

This paper has analyzed the effects of the characteristics of the previous job on the reemployment probability of displaced workers with a focus on the signalling hypothesis developed by Gibbons and Katz (1991). This is done by looking at how the conditions leading to displacements affect the employees' reemployment perspectives. The novelty of the paper is that the data used are flow data constructed from administrative registers which makes us able to follow workers from the week they become unemployed and until the week they get a new job or leave the labour force as opposed to the yearly transitions conventionally studied in this literature.

We have applied a competing risk model where exits are either back into employment or into inactivity. The main result is that workers who have lost their job because of a plant closure get a new job faster than workers who have experienced a severe downsizing of their workplace. Furthermore, both of these groups return to employment faster than employees displaced due to individual lay-offs. The interpretation is that this is due to a signalling effect as described by Gibbons and Katz. Though the result is not new to the literature in itself, it is the first time where it is found that the signalling effect is present in cases of severe downsizing. Furthermore, in contrast to previous findings we show that all educational groups (hourly waged and salaried waged) are affected by signalling. Finally, it is established that there is a clear positive tenure effect on the re-employment probability for those who have lost their job through a workplace shutdown but not for 
other workers. This demonstrates that the workplace-specific human capital in these workplaces can often be used in other workplaces. A similar result is not found for downsizing workplaces.

\begin{abstract}
A strong policy advice can be derived directly from our study. The analysis makes it clear that workers displaced from workplace closures and from workplaces facing severe downsizing are relatively successful in regaining employment compared to other job losers. This implies that it seems much more appropriate to use labour market policy resources on the latter group. Adding to this is that firm-specific human capital in closing workplaces to a large extent is made useful at other firms in the sense of Schumpeterian creative destruction.
\end{abstract}




\section{References}

Doiron, J. D., 1995, Lay-offs as Signals: the Canadian Evidence, The Canadian Journal of Economics, 28: pp. 899-913.

Farber, H. S., 1994, The Analysis of Interfirm Worker Mobility, Journal of Labor Economics, Vol. 12, pp. 554-593.

Frederiksen, A. and E. Takáts, 2005, Layoffs as Part of an Optimal Incentive Mix: Theory and Evidence, Industrial Relations Section Working Paper \# 502, Princeton University.

Frederiksen, A. and N. Westergaard-Nielsen, 2006, Where Did They go? Modeling Transitions Out of Jobs, Forthcoming in Labour Economics

Frijters, P. and B. van der Klaauw, 2003, Job Search with Nonparticipation, CEPR Discussion Papers \# 3922.

Gibbons, R. and L. Katz, 1991, Layoffs and Lemons, Journal of Labor Economics, Vol. 9, pp. 351-380.

Heckman, J. J., 1981, Heterogeneity and State Dependence, In Studies in Labor Markets edited by Sherwin Rosen, Chicago: University of Chicago Press.

Heckman, J. J. and G. Borjas, 1980, Does Unemployment Cause Future Unemployment? Definitions, Questions and Answers from a Continuous Time Model of Heterogeneity and State Dependence, Special Symposium Issue on Unemployment, Economica, pp. 247-83.

Narendranathan, W. and M. B. Stewart, 1993, How does the Benefit Effect vary as Unemployment Spells Lengthen?, Journal of Applied Econometrics, Vol. 8, pp. 361-81.

Neal, D., 1995, Industry-Specific Human Capital: Evidence from Displaced Workers, Journal of Labor Economics, Vol 13, pp. 653-77.

Meyer, B., 1990, Unemployment Insurance and Unemployment Spells, Econometrica, Vol. 58, pp. 757-782.

Mortensen, D. T. and C. Pissarides, 1999a, Job reallocation and employment fluctuations, in M. Woodford and J. B. Taylor, eds., Handbook of Macro Economics, vol. 1: pp. 11711227. Amsterdam: Elsevier Science. 
Mortensen, D. T. and C. Pissarides, 1999b, New developments in Models of Search in the Labor Market, in O. Ashenfelter and D. Card, eds., Handbook of Labor Economics, vol. 3: pp. 2567-2627. Amsterdam: Elsevier Science.

Rosholm. M. and O. Toomet, 2005, A Search Model of Discouragement, IZA Discussion Papers \# 1633, Institute for the Study of Labor (IZA). 


\section{Appendix}

Table A1. Definitions and descriptions of the not self-explanatory variables.

\begin{tabular}{|c|c|}
\hline Duration first E-spells (weeks) & Tenure in the job the person leaves \\
\hline Experience (years) & Years of experience in the labour marked \\
\hline $\begin{array}{l}\text { Unskilled } \\
\text { Preparation/specialized courses } \\
\text { Vocational training } \\
\text { High school } \\
\text { Short theoretical education } \\
\text { Bachelors degree } \\
\text { Masters or PhD degree }\end{array}$ & $\begin{array}{l}\text { Primary school } \\
\text { Courses after primary school, not formal education } \\
\text { Secondary school } \\
\text { Short higher education } \\
\text { Medium long higher education } \\
\text { Long higher education }\end{array}$ \\
\hline $\begin{array}{l}\text { Live in the capital } \\
\text { Live outside the capital }\end{array}$ & $\begin{array}{l}\text { Live in Copenhagen } \\
\text { Live in the provinces }\end{array}$ \\
\hline $\begin{array}{l}\text { Work in the capital } \\
\text { Work outside the capital }\end{array}$ & $\begin{array}{l}\text { Work in Copenhagen } \\
\text { Work in the provinces }\end{array}$ \\
\hline $\begin{array}{l}\text { Children0-6 } \\
\text { Children7-17 }\end{array}$ & $\begin{array}{l}\text { Children aged 0-6 living in the household } \\
\text { Children aged } 7-17 \text { living in the household }\end{array}$ \\
\hline \multicolumn{2}{|l|}{ Plant status } \\
\hline Unchanged $(+/-10 \%)$ & $\begin{array}{l}\text { Same number of employees in the plant in year } t \text { and year } \\
t-1 \text {. To avoid influence from small changes, upsize and } \\
\text { downsize less than } 10 \% \text { of the number of employees are } \\
\text { categorized as unchanged }\end{array}$ \\
\hline Upsize & $\begin{array}{l}\text { The number of employees increases } 10-100 \% \text { from year } \\
t-1 \text { to year } t\end{array}$ \\
\hline Downsize $10-50 \%$ & $\begin{array}{l}\text { The number of employees in the plant has dropped } 10- \\
50 \% \text { from year } t-1 \text { to year } t\end{array}$ \\
\hline Downsize $50-99 \%$ & $\begin{array}{l}\text { The number of employees in the plant has dropped } 50 \text { - } \\
99 \% \text { from year } \mathrm{t}-1 \text { to year } \mathrm{t}\end{array}$ \\
\hline Closed & The plant exists in year $t$ but is closed in year $t+1$ \\
\hline
\end{tabular}

